Fixed Point Theory, 20(2019), No. 2, 523-540

DOI: $10.24193 /$ fpt-ro.2019.2.34

http://www.math.ubbcluj.ro/ nodeacj/sfptcj.html

\title{
EXTRAGRADIENT AND LINESEARCH ALGORITHMS FOR SOLVING EQUILIBRIUM PROBLEMS, VARIATIONAL INEQUALITIES AND FIXED POINT PROBLEMS IN BANACH SPACES
}

\author{
ZEYNAB JOUYMANDI* AND FRIDOUN MORADLOU**,1 \\ ${ }^{*}$ Department of Mathematics, Sahand University of Technology, Tabriz, Iran \\ E-mail: z_jouymandi@sut.ac.ir \& z.juymandi@gmail.com \\ ** Department of Mathematics, Sahand University of Technology, Tabriz, Iran \\ E-mail: moradlou@sut.ac.ir \& fridoun.moradlou@gmail.com
}

\begin{abstract}
Using generalized metric projection, new extragradient and linesearch algorithms are presented for finding a common element of the solution set of an equilibrium problem and the solution set of variational inequality problem which is also an element of the set of fixed points of a weakly relatively nonexpansive mapping in Banach spaces. To prove strong convergence of the iterates in the extragradient method, a $\phi$-Lipschitz-type condition is introduced and is assumed that the equilibrium bifunction satisfies in this condition. To avoid using this condition, the linesearch method is applied instead of the extragradient method. Using FMINCON optimization toolbox in MATLAB, some numerical examples are given to illustrate the usability of obtained results.

Key Words and Phrases: Equilibrium problem, extragradient method, $\phi$-Lipschitz-type, generalized metric projection, linesearch algorithm, relatively nonexpansive mapping.
\end{abstract}

2010 Mathematics Subject Classification: 65K10, 90C25, 47J05, 47J25.

Acknowledgement. The authors would like to thank the referee(s) for precise consideration and valuable comments.

\section{REFERENCES}

[1] R.P. Agarwal, D. O'Regan, D.R. Sahu, Fixed Point Theory for Lipschitzian-Type Mappings with Applications, Springer, New York, Topological Fixed Point Theory and Its Applications, 6, 2009.

[2] S. Alizadeh, F. Moradlou, A strong convergence theorem for equilibrium problems and generalized hybrid mappings, Mediterr. J. Math., (2016), 13(1), 379-390.

[3] P.N. Anh, A hybrid extragradient method extended to fixed point problems and equilibrium problems, Optimization, 62(2013), 271-283.

[4] A.S. Antipin, The convergence of proximal methods to fixed points of extremal mappings and estimates of their rates of convergence, Comput. Maths Math. Phys., 35(1995), 539-551.

[5] E. Blum, W. Oettli, From optimization and variational inequality to equilibrum problems, The Mathematics Student, 63(1994), 127-149.

\footnotetext{
${ }^{1}$ Corresponding author.
} 
[6] L.C. Ceng, Q.H. Ansari, S. Schaible, Hybrid extragradient-like methods for generalized mixed equilibrium problems, systems of generalized equilibrium problems and optimization problems, J. Global Optim., 53(2012), 69-96.

[7] L.C. Ceng, Q.H. Ansari, M.M. Wong, J.C. Yao, Mann type hybrid extragradient method for variational inequalities, variational incusions and fixed pont problems, Fixed Point Theory, 13(2012), no. 2, 403-422.

[8] L.C. Ceng, C.F. Wen, Y. Yao, Relaxed extragradient-like methods for systems of generalized equilibria with constraints of mixed equilibria, minization and fixed point problems, J. Nonlinear Var. Anal., 1(2017), 367-390.

[9] S.Y. Cho, Generalized mixed equilibrium and fixed point problems in a Banach space, J. Nonlinear Sci. Appl., 9(2016), 1083-1092.

[10] Y.J. Cho, H. Zhou, G. Guo, Weak and strong convergence theorems for three-step iterations with errors for asymptotically nonexpansive mappings, Comput. Math. Appl., 47(2004), 707-717.

[11] G. Cohen, Auxiliary problem principle and decomposition of optimization problems, J. Optimiz. Theory Appl., 32(1980), 277-305

[12] G. Cohen, Auxiliary principle extended to variational inequalities, J. Optim. Theory Appl., 59(1988), 325-333.

[13] B.V. Dinh, L.D. Muu, A projection algorithm for solving pseudomonotone equilibrium problems and its application to a class of bilevel equilibria, Optimization, 64(2015), 559-575.

[14] C. Gang, B. Shangquan, Weak convergence theorems for general equilibrium problems and variational inequality problems and fixed point problems in Banach spaces, Acta Mathematica Scientia, 33B(1)(2013), 303-320.

[15] H. Induka, W. Takahashi, Strong convergence by hybrid type method for monotone operators in a Banach space, Nonlinear Anal., 68(2008), 3679-3688.

[16] Z. Jouymandi, F. Moradlou, Retraction algorithms for solving variational inequalities, pseudomonotone equilibrium problems and fixed-point problems in Banach spaces, Numer. Algorithms, 78(2018), 1153-1182.

[17] Z. Jouymandi, F. Moradlou, J-variational inequalities and zeroes of a family of maximal monotone oprators by sunny generalized nonexpansive retraction, Comput. Appl. Math., 37(2018), 5358-5374.

[18] S. Kamimura, W. Takahashi, Strong convergence of proximal-type algorithm in Banach space, SIAM J. Optim., 13(2002), 938-945.

[19] G.M. Korpelevich, The extragradient method for finding saddle points and other problems, Ekon. Mat. Metody., 12(1976), 747-756.

[20] G. Mastroeni, On auxiliary principle for equilibrium problems, Publ. del Dipartimento di Mathematica dell'Universita di Pisa, 3(2000), 1244-1258.

[21] L.D. Muu, W. Oettli, Convergence of an adaptive penalty scheme for finding constrained equilibria, Nonlinear Anal. TMA, 18(1992), 1159-1166.

[22] L.D. Muu, T.D. Quoc, Regularization algorithms for solving monotone Ky Fan inequalities with application to a Nash-Cournot equilibrium model, J. Optim. Theory Appl., 142(2009), 185-204.

[23] T.T.V. Nguyen, J.J. Strodiot, V.H. Nguyen, The interior proximal extragradient method for solving equilibrium problems, J. Global Optim., 44(2009), 175-192.

[24] X. Qin, Y.J. Cho, S.M. Kang, Convergence theorems of common elements for equilibrium problems and fixed point problems in Banach spaces, J. Comput. Appl. Math., 225(2009), 20-30.

[25] X. Qin, Y.J. Cho, S.M. Kang, Strong convergence of shrinking projection methods for quasi- $\phi$ nonexpansive mappings and equilibrium problems, J. Comput. Appl. Math., 234(2010), 750-760.

[26] X. Qin, J.C. Yao, Projection splitting algorithms for nonself operators, J. Nonlinear Convex Anal., 18(2017), 925-935.

[27] R.T. Rockfellar, Monotone operators and the proximal point algoritm, SIAM J. Control Optim., 14(1976), 877-808.

[28] J.J. Strodiot, T.T.V. Neguyen, V.H. Neguyen, A new hybrid extragradient algorithms for solving quasi-equilibrium problems, J. Global Optim., 56(2013), 373-397.

[29] W. Takahashi, Nonlinear Functional Analysis, Yokohama Publishers, Yokohama, 2000. 
[30] Y. Takahashi, K. Hashimoto, M. Kato, On sharp uniform convexity, smoothness, and strong type, cotype inegualities, J. Nonlinear Convex Anal., 3(2002), 267-281.

[31] W. Takahashi, K. Zembayashi, Strong and weak convergence theorems for equilibrium problems and relatively nonexpansive mappings in Banach spaces, Nonlinear Anal., 70(2009), 45-57.

[32] D.Q. Tran, L.D. Muu, V.H. Nguyen, Extragradient algorithms extended to equilibrium problems, Optimization, $\mathbf{5 7}(2008), 749-776$.

[33] N.T.T. Van, J.J. Strodiot, V.H. Nguyen, A bundle method for solving equilibrium problems, Math. Program., 116(2009), 529-552.

[34] P.T. Vuong, J.J. Strodiot, V.H. Nguyen, Extragradient methods and linesearch algorithms for solving Ky Fan inequalities and fixed point problems, J. Optim. Theory Appl., 155(2012), 605627.

[35] H. Zegeye, N. Shahzad, Strong convergence theorems for variational inequality problems and quasi- $\phi$-asymptotically nonexpansive mappings, J. Global Optim., 54(2012), 101-116.

Received: February 8, 2017; Accepted: October 11, 2018. 
